\title{
Leituras Acerca do Manifesto dos Pioneiros da Educação Nova De 1932: Uma Análise para além da Educação
}

\author{
Edilânio Rodrigues Macário ${ }^{1}$ Ítalo Ramom Santos Bandeira² ; Kátia Maria de Moura ${ }^{3}$
}

\begin{abstract}
Resumo: Este estudo é uma análise acerca do Manifesto dos Pioneiros da Educação Nova de 1932, documento que marca historicamente a educação num viés revolucionário. Nessa linha, para entender a elaboração e publicação deste documento, fez-se necessário resgatar o cenário sócio-histórico e político da época, pois sem esta compreensão inviabilizaria o real conhecimento dos motivos que culminaram no referido documento que marcou não só uma década, mas faz parte da história educacional brasileira.
\end{abstract}

Palavras-chave: Educação Brasileira. Reforma Educacional. Educação Nova.

\section{Readings About the New Education Pioneers Manifesto of 1932: An Analysis Beyond Education}

\begin{abstract}
This study will discuss understandings about the New Education Pioneers Manifesto of 1932, a document that historically marks education in a revolutionary bias. In order to understand the elaboration and publication of this document, it was necessary to recover the socio-historical and political scenario of the time, because without this understanding it would not make possible the real knowledge of the reasons that culminated in the mentioned document that marked not only a decade, but is part of the Brazilian educational history.
\end{abstract}

Keywords: Brazilian Education. Educational Reform. New Education.

\section{Introdução}

Buscamos nesse estudo refletir sobre o Manifesto dos Pioneiros da Educação Nova de 1932, o documento refere-se ao período como de grande Otimismo Pedagógico ou "Grande Reforma", dada a sua relevância enquanto tal.

\footnotetext{
${ }^{1}$ Licenciado em História pela Universidade Regional do Cariri, Especialista em História do Brasil pela Universidade Regional do CaririURCA. Aluno do Programa de Mestrado Profissional em Educação - MPEDU da URCA.

Contato: macario1500@gmail.com;

${ }^{2}$ Graduado em Geografia pela Universidade Regional do Cariri, Especialista em Práticas Docente do Ensino Superior pela Faculdades Integradas de Patos. Aluno do Programa de Mestrado Profissional em Educação - MPEDU da URCA.

Contato: italo.geo20@gmail.com;

${ }^{3}$ Graduada em Licenciatura Plena em Pedagogia pela Universidade Federal do Piauí, Especialista em Gestão do Trabalho Pedagógico pela Faculdade Internacional de Curitiba. Aluna do Programa de Mestrado Profissional em Educação - MPEDU da URCA. Contato: professorakatiamoura@gmail.com.
} 
Há de ser dito que este estudo não tem a pretensão de minimizar a importância do documento ou vangloriá-lo, mas contextualizá-lo no cenário de transições e transformações econômicas e políticas, elucidando sua função para a época e suas implicações ou contribuições até a atualidade. Com base nestas premissas, buscaremos fazer uma análise da relação do Manifesto de 1932 com processo de industrialização do Brasil, o que nos conduz a uma breve reflexão acerca do conceito de modernidade e sua empregabilidade no contexto nacional.

Em vista disso, o cenário sociopolítico brasileiro da década de 1930 é marcado por fortes transformações que vão desde o aumento da população e demanda das necessidades urbanas até à industrialização e as consequências da Revolução de 1930. Isso se dá devido a ascensão de Getúlio Vargas ao poder, quando assume provisoriamente o governo e entre suas primeiras ações no campo da Educação cita-se a criação do Ministério da Educação e Saúde Pública com imediata nomeação de Francisco Campos. Este, por sua vez, assina um conjunto de sete decretos referente às Reformas Educacionais que ficaram conhecidas com seu nome: Reforma Francisco Campos. Tais reformas abrangeram desde tentativas de organização dos graus de escolarização à instituição do ensino religioso nas escolas oficiais públicas.

Com efeito, Getúlio Vargas assume o Governo e em seus discursos demonstra plena preocupação com a educação, embora revestido de interesses diversos. Algumas reformas, mesmo que fragmentadas ou sem caráter científico educacional, situadas na década de 1920, permitiram a chegada de profissionais da educação que, mesmo divergindo ideologias diferentes quanto às influências da Igreja na educação, convergiam quanto a esta, devendo ser democrática, fundamentada em princípios filosóficos, sociológicos e científicos. Ou seja, pretendiam uma educação, acima de tudo, organizada e fundamentada. Fundaram, então, a Associação Brasileira de Educação.

O Manifesto dos Pioneiros da Educação Nova se constitui como um documento emblemático, o qual nos permite uma reflexão endossada nas bases políticas e sociais desta época, fermentando ideários que estavam ali postos e que disputavam interesses variados nas mais diversas esferas: política, econômica, social e cultural.

\section{Aspectos Históricos}

Ao pensar sobre o Manifesto dos Pioneiros no Brasil, percebe-se que este emerge numa ascensão de Getúlio Vargas ao poder, o que nos convida a situar todo o processo que conduziu a este período histórico de grandiosa relevância para nossa tessitura política e educacional. Nesse sentido, após a Revolução de 1930, o Estado brasileiro sai de uma economia baseada na agroindústria para um surto 
econômico que apostaria na indústria para mudar o país. Por meio deste, é necessário promover uma reflexão crítica sobre este documento que fez parte de um conjunto que compõe a História da Educação no Brasil.

No período entreguerras, milhões de identidades compartilhavam um conjunto comum de experiências educacionais. Essas experiências foram o produto de políticas cuidadosamente elaboradas por uma reduzida elite administrativa, técnica e intelectual que tinha um senso concentrado e deliberado da importância da raça não apenas para as escolas, mas para o Brasil (DÁVILA, 2006, p. 46).

É sabido que o Manifesto dos Pioneiros da Educação Nova foi um documento que continha interesses, os quais estavam efetivamente atrelados com a formação de uma "raça" e de um "homem brasileiro", com uma engenharia racial e social bem definidas.

É imperioso reforçar que com a proclamação da República, em 1889, até 1930, o Brasil vivia num ritmo eminentemente pautado no setor agrário, o que facilitava as práticas coronelistas, de mandonismo, filhotismo e clientelistas características desse período. Sustentados por uma elite que estava alicerçada pela economia cafeeira, percebemos dentro desse interstício a emergência de oligarquias que dominariam o cenário brasileiro por décadas. Grassavam neste momento, políticas que direcionavam olhares apenas para interesses de grandes empresários e setores elitizados, deixando de lado os investimentos em educação, por exemplo.

A constituição vigente nesse momento era a de 1891, que, promulgada, constituía-se como a primeira republicana e a segunda da história do Brasil, tinha como característica maior a exclusão dos trabalhadores, como podemos verificar no estrato abaixo:

A rigor, porém, não existia nenhum dispositivo legal que impedisse a participação política e eleitoral do trabalhador. A República aboliu o voto censitário, que concedia direitos eleitorais somente a pessoas com certa renda ou propriedade. O sufrágio tornou-se universal, embora tal conceito significasse a participação de poucos. Na prática, a participação ficava restrita aos brasileiros (ou naturalizados), maiores de 21 anos, do sexo masculino, alfabetizados e que não fossem mendigos, soldados sem patente de oficial ou membros de ordens religiosas. $\mathrm{O}$ voto não era obrigatório (DE OLIVEIRA, 2006, p. 6)

Assim, vivia-se à base de uma política centrada na alternância de presidentes de dois partidos republicanos situados em Minas Gerais e São Paulo (Política do café com leite), num sistema político denominado Política dos Governadores, no qual um candidato era eleito com base na escolha de um coronel da região, interligando os poderes municipal, estadual e federal. Uma série de transformações que agitavam nossa realidade desde os anos 1920, nos governos de Artur Bernardes, dava ao Brasil um ideal de modernidade, principalmente no âmbito educacional, vivido com a Semana de Arte Moderna de 1922 em São Paulo, os movimentos liderados pelo Tenentismo, o movimento operário, a criação do PCB (Partido Comunista Brasileiro), como acontecimentos que fervilhavam na década de 1920. 
Todavia, a indicação de um gaúcho à presidência no final da década de 1920 quebra esta rotatividade da política, incomodando aos elitistas vigentes da época, na sua maioria, cafeicultores. "Para enfrentar tal coligação de interesses, Vargas articulou em torno de si vários grupos que, desde o início da década de 1920, vinham dando mostra de descontentamento contra o domínio oligárquico (DEL PRIORE e VENÂNCIO, p. 180).

Com efeito, Getúlio se consagra Presidente da República, quebrando uma alternância entre o PRP (Partido Republicano Paulista) e PRM (Partido Republicano Mineiro), na denominada Política do Café com Leite. Enfrentou uma instabilidade muito grande em seus primeiros anos de Governo, vez que o fez que chegando cambaleante, mas ia conseguindo se erguer aos poucos.

Nas palavras de Saviani (2008, p. 191):

Firmou-se na historiografia a seguinte interpretação: não havendo nenhum grupo com legitimidade para assumir o controle governamental, teria emergido do movimento vitorioso um "Estado de compromisso", sustentado pelo Exército que passou a operar como um liame unificador das várias frações da classe dominante.

Todavia, no tocante ao cenário educacional, percebe-se que havia um fosso grandioso entre as propostas elitistas e a realidade social dos trabalhadores, como se apura a seguir:

No entanto, apesar dos "esforços" do empresariado, as lutas de classe não cessaram, e suas medidas paliativas não materializaram as chamadas "liberdades democráticas", enquanto forma de dominação burguesa, presente em algumas nações capitalistas hegemônicas. Nesse sentido, nem a educação pública estava na pauta das elites, apesar do discurso de alguns de seus representantes, fato que não deve causar estranheza para ninguém. A situação era de omissão (DE OLIVEIRA, 2006, p. 10)

É imperioso perceber que o cenário brasileiro estava marcadamente assolado por altos índices de analfabetismo da população, um domínio oligárquico extremamente concentrado nas mãos de poucos e a sede em fazer do Brasil um país à moda estrangeira, modernizando-o e civilizando a população sob um viés industrial. Destaca-se nesse processo a implantação das ferrovias no Brasil que, conforme Saviani, "constituíram-se na base de um processo de urbanização e industrialização" (2008, p. 188).

No Cariri cearense não foi diferente, experienciamos uma época do Pacto dos Coronéis e também de uma Sedição de 1914. Grupos enormes de pessoas buscando fuga em um líder messiânico que supostamente teria a solução para suas mazelas sociais, como a fome, as injustiças sociais, a desesperança com a vida. Seduzidos pelo fervor religioso, somando-se à carência espiritual, física e a vida sofrida, muitos romeiros vão dedicar sua fé em torno do Padre Cícero Romão Batista, buscando uma reparação à vida de exclusão que levavam.

Nesse contexto, podemos observar ainda as críticas dos movimentos que emergiam neste período à ordem estritamente burguesa que ditava as normas até para a educação: 
A principal crítica dirigida à educação burguesa dizia respeito ao seu caráter ideológico. Em outras palavras, a escola se constitui em um instrumento de reprodução dos preconceitos presentes na sociedade burguesa. Trata-se, dentro da perspectiva anarquista, de romper o círculo vicioso entre a miséria material dos trabalhadores, a ignorância e o preconceito, de instrumentalizar o proletariado na formação de indivíduos autônomos, críticos, solidários e amantes da liberdade (DE OLIVEIRA, 2006, p. 14)

País calcado em muitas contradições sociais, com um ranço do coronelismo vivido explicitamente por anos, Getúlio rompe com os modelos vigentes até então e abre portas para as manifestações críticas dos setores mais pobres da população brasileira.

Com a Revolução de 1930, percebe-se que já se direcionava para uma legislação trabalhista, a qual ceifava todas as lutas que vinham vigorando até então e tendia a beneficiar determinada categoria social, como se vê abaixo:

Para o Estado, a legislação trabalhista tinha uma finalidade especial: impedir a organização autônoma dos trabalhadores. Evidentemente, essa ofensiva do Estado contribuiu para silenciar propostas oriundas do proletariado. Por outro lado, o movimento escolanovista expressou o ideal liberal de ascensão pela educação, o que contribui para o não questionamento das bases materiais da desigualdade (DE OLIVEIRA, 2006, p. 23).

A conjuntura de 1932, trazia ao Brasil a Revolução constitucionalista que requeria uma nova Constituição para o país, que estava precisando ser modificada desde sua última, de 1891. As novas roupagens visualizadas no país, pediam uma nova forma de governar, dando abertura para formas alternativas de se fazer política e envolver os setores marginalizados da população, consoante se nota no trecho:

A denominada Revolta Constitucionalista, embora derrotada, alcança parte importante de seus objetivos. Além da confirmação da convocação da Assembleia Constituinte, os paulistas influenciaram a escolha do interventor local, Armando de Salles Oliveira. O mérito de Getúlio foi o de ter conseguido permanecer no poder. Mas a situação o fragilizava (DEL PRIORE e VENÂNCIO, p. 181).

Com base nessas premissas, o cenário educacional também requeria uma nova cara, o que foi dado a partir da eclosão do Manifesto dos Pioneiros da Educação Nova de 1932. Assumia-se aqui uma nova forma de se fazer educação no país, de forma "modernizante", como previam seus mentores. A ideia era acompanhar os imigrantes que vinham de fora com novas ideias e que viam no país certo "atraso" neste quesito.

Pensava-se em trazer novas formas de enxergar e lidar com a educação. Nesse sentido, via-se como alternativa a qualificação destes trabalhadores, traduzindo o real sentido para aquela proposta de mudança dos moldes educacionais vigentes. Visava-se, com isso, uma clara implantação do 
nacionalismo e do civismo, oriundos de influências externas. A ideias era educar o Brasil, começando pelo espaço educacional, como percebemos abaixo:

Algo tão simples e tão íntimo como comer, escovar os dentes ou lavar as mãos atividades repetidas incessantemente no espaço privado dos lares - se tornou o sujeito de políticas públicas desenvolvidas para deter a degeneração da nação e salvar o Brasil (DÁVILA, 2006, p. 41).

A influência da promessa industrial se atrelava ao campo da Educação, configurando-se como uma possível saída, com clara hegemonia burguesa:

O elo entre a indústria e a educação era mais do que casual e se estendia muito além da esfera da educação vocacional. Muitos educadores, como Fernando de Azevedo e Manoel Lourenço Filho, também participaram de projetos que visavam a racionalizar a força de trabalho na indústria (DÁVILA, 2006, p. 34).

É contundente destacar que esta ebulição social que vivia o país desde a década de 1920 contribuiu para a consolidação de um aspecto urbano e industrial que emergia em consonância com as reivindicações religiosas vigentes na época, as quais não iriam aceitar de bom grado as propostas que surgiam. No entanto, como se reitera a seguir:

\footnotetext{
A industrialização acelerada teve efeitos não só econômicos, mas também políticos e sociais. Como é sabido, a fábrica tem na cidade seu espaço privilegiado e, por isso, a Era Vargas - incluindo aí seu segundo governo, entre 1950 e 1954 - é caracterizada como uma época de intensa urbanização. Em 1920, por exemplo, apenas dois em cada dez brasileiros residiam em cidades; vinte anos mais tarde essa mesma relação era de três para dez; na década de 1940, tal proporção tornara-se equilibrada: quatro em cada dez brasileiros moravam em áreas urbanas (DEL PRIORE e VENÂNCIO, 2010, p. 185).
}

Portanto, a conjuntura em que se instalava as ideias educacionais nesse momento estavam diretamente atrelados aos movimentos políticos, sociais e econômicos que se entrecruzavam na década de 1930 e com influências anteriores. As direções estavam pautadas em condições que adequavam os interesses elitistas ao cenário vivido pelo país, tanto em questões nacionais quanto aos fatores externos ao país que direcionavam a mudanças.

\section{Industrialização e Modernização no Brasil}

Dentro das perspectivas abordadas acima, pensamos que para analisar a relação do Manifesto de 1932 com processo de industrialização do Brasil, faz-se necessária uma breve reflexão acerca da do 
conceito de modernidade e sua empregabilidade no contexto nacional, assim como este conceito reverbera dentro deste cenário.

Partimos do pressuposto de que "a revolução Industrial ocorrida na Inglaterra nos ídolos do século XVIII contrapondo o estágio de desenvolvimento neolítico iniciado em outras partes do globo há 10.000 anos e que ainda vivíamos em meados do século XVI no momento do contato com os europeus" (QUEIROZ, 2002, p.44), e podemos atestar certa desvantagem temporal se tomarmos a industrialização como condição à modernização de uma nação.

Em razão disso, os problemas enfrentados residem na tentativa de propor a modernização dos países latino-americanos a partir de uma perspectiva europeia e ou norte-americana, tomando o outro como base na construção de sua identidade sem levar em consideração suas especificidades, "atribuindo assim, ao conceito de modernização o sinônimo de europeização ou ocidentalização" (QUEIROZ, 2002, p.44 e 45).

Nesse sentido, o Brasil, nesse período, "lutava para se ajustar a uma forma de vida que se mostrasse mais identificada com países, nos quais o desenvolvimento do capital, como ordem produtiva, já havia passado por grandes avanços" (MUZZUCO e TULLIO, 2004, p.01) sendo, a modernização alicerçada por um tripé de equilíbrio, como aponta Queiroz:

[...] nos países da Europa ocidental, onde nasceu, e reduzida às suas expressões mais simples, a modernização pode caracterizar-se como um processo de mobilização, diferenciação e laicização". Com o termo mobilização quer-se indicar a facilidade e a rapidez com que os bens, as pessoas, as informações circulam no interior de uma mesma sociedade. O termo diferenciação relaciona a modernização com a divisão do trabalho, considerando que nas sociedades modernas empregos e status são menos rigidamente distribuídos do que nas sociedades europeias até o século XV. Finalmente, laicização não significa a presença ou ausência de crença[...] (202, p. 44).

Contudo, o país não possuía nenhuma dessas três características, com extensão territorial de dimensões continentais e uma história econômica marcada pela formação de um arquipélago econômico, sua mobilização era deficitária diante das dificuldades geográficas de intersecção das regiões, sua diferenciação ainda estava em processo de formação, visto que tratava-se de uma sociedade em transição e há pouco ainda era de estrutura escravocrata, a laicização era algo definitivamente urgente, a igreja ainda possui laços estreitos com o estado e essa relação era vista pelos ideários de modernização como prejudicial.

Das três demandas apresentadas, a laicização representava imediata evidência, pois representava a mudança de hábitos culturais, o incentivo à produção, ao consumo, a aproximação da ciência moderna, via institucionalização do saber em que o homem era o centro das relações de poder. Logo, "é a separação instituída entre a Igreja (e também o Estado) e, do outro lado, as instituições de 
pesquisa e de ensino. O processo de modernização não se confunde, necessariamente, com o processo de industrialização[...]" (QUEIROZ, 2002, p.45).

Nesse sentido, a educação teria papel importante no contexto de modernização do país, a qual necessitava concluir a ruptura com a igreja. Concluir, pois, através das tentativas de construção de um sistema educacional, desde 1759, quando a administração da colônia passa a ser responsabilidade do Marquês de Pombal, influenciado por ideais iluministas como o antropocentrismo, "ocorrerá as primeiras iniciativas de questionamento dessa relação, o mesmo irá realizar a expulsão dos Jesuítas da Colônia e iniciar uma série de reformas no ensino" (SAVIANI, 2008, p. 77).

Porém, apenas 173 anos depois essa ruptura seria possível, já que "o Manifesto representou um marco na renovação educacional do Brasil, os pioneiros assumiram a missão de conduzir o Brasil à Modernidade pela via da Educação" (VIEIRA, 2006, p.01), e essa não podia ser concebida se não pela ótica da laicidade. Dessa maneira,

A Escola passou a ser vista, nesta compreensão, como o loco principal para desenvolver no individuo toda uma sensibilidade para querer ser o homem traduzido pela filosofia política: trabalhador e cidadão. Neste sentido, o Documento teve para com a educação um caráter pragmático de aceleramento das mudanças desejadas (MUZZUCO e TULLIO, 2004, p.01).

Destacam-se nesse momento três aspetos que influenciaram o manifesto de 1932: um país eminentemente agrário, em que a preocupação com a formação intelectual não se fazia necessária, indo em direção à industrialização com uma gama de analfabetos, o que exigia repensar a educação visando à qualificação dos trabalhadores. Além disso, a presença de imigrantes bem instruídos gerou questionamentos a respeito do sistema de educação e ensino brasileiro. E por fim, a influência do Estado no processo de construção do Manifesto dos Pioneiros da Educação Nova, como evidencia Vieira:

\footnotetext{
A produção do Manifesto na IV Conferência Nacional de Educação (CNE) foi resultado de uma solicitação do governo, o qual teve ativa participação durante a Conferência. [...] teve a ativa participação do Ministro da Educação e Saúde Pública, Francisco Campos, o qual convocou pessoalmente as delegações estaduais para participarem da IV CNE tendo em vista sua importância. Esses fatos apontam para uma estreita relação entre o Estado e a ABE [...] (2006, p.02).
}

Neste contexto, o Manifesto pode ser pensado como base política e de modernização que alicerçaria a educação até os dias de hoje, o qual acaba, "legitimando um grupo de intelectuais da educação que visavam salvar o país do seu atraso e levá-lo a modernização por meio da educação, sendo eles os agentes ou heróis dessa mudança" [...] (VIEIRA, 2006, p.08). 


\section{Associação Brasileira de Educação}

A Associação Brasileira de Educação - ABE - Fundada por volta de 1924, "teve organização nacional em 1932. Caracterizado como órgão apolítico, "intencionou reunir interessados na causa da educação, independente das ideologias filosóficas ou religiosas" (SAVIANI, 2013. p.229). Num clima social de disputas e interesse de manutenção do poder, tanto o governo almejava conquistar o espaço da $\mathrm{ABE}$ quanto a $\mathrm{ABE}$ pretendia se apropriar do governo para difundir suas ideias pedagógicas. Por isso, havia aproximação e coerência nas falas e intenções de ambos os lados.

Eis que a ABE fica encarregada de organizar a IV Conferência Nacional de Educação, a qual foi realizada em Dezembro de 1931. Na oportunidade Vargas acompanhado do ministro da Educação Francisco Campos, contrariando a pauta e surpreendendo aos educadores presentes na Conferência, solicita aos inscritos que definissem as Bases Políticas Da Educação (SAVIANI, 2007, p.230).

Conforme Saviani (2007, p.231), "a base dirigente da ABE composta por favoráveis à influência do ensino religioso e por outros contra, porém esse conflito até então mantinha-se velado até este momento". Pois, Nóbrega da Cunha aproveita de tal solicitação para externar tal discordância culminando na cisão do grupo, aceita o desafio de elaborar um documento com as Diretrizes, mas contrapropõe que pela seriedade, tal documento merece dedicação e preparo, pois não estando na pauta no evento não poderia ter tal solicitação contemplada.

O então presidente da IV Conferência acata o pedido de Nóbrega da Cunha e solicita que seu requerimento seja incluído na pauta para discussão para V Conferência Nacional de Educação que seria realizada no ano de 1933. No entanto, por se tratar de estratégia de Nóbrega da Cunha, em Março de 1933 tal documento é publicado nomeado como Manifesto dos Pioneiros da Educação Nova, destinada ao povo e ao governo. Tendo a incumbência de disseminar e lutar por uma profunda e radical transformação da educação em todos os seus graus.

O Manifesto, de acordo com Saviani (2007, p. 241) consta de:

Introdução: Movimentos de renovação educacional; Diretrizes que se esclarecem; Reforma e a Reforma. 1 Os Fundamentos filosóficos e sociais da educação; Finalidade da Educação; Valores Mutáveis e Permanentes; 2 A organização e administração do sistema educacional: o estado em face da educação; a) A educação, uma função essencialmente pública; b) a questão da escola única; c) a laicidade, gratuidade, e coeducação; A função educacional a) a unidade da função educacional; b) a autonomia educacional; c) a descentralização. 3 As bases psicobiológicas da educação: $O$ processo educativo; o conceito e os fundamentos da educação Nova; 4 Planejamentos do sistema, conforme os princípios e diretrizes enunciados: Planos de reconstrução educacional a) as Linhas gerais do plano; b) o conceito moderno de universidade e o problema universitário no Brasil; c) o problema dos melhores. A Unidade de formação de professores e a unidade de espírito; O Papel da escola na vida e na função social Conclusão: A democracia - um programa de longo deveres. 
Com efeito, o Manifesto fora assinado por 26 educadores, unidos na missão de construir um sistema organizado educacional, contando com três educadores de destaque: Fernando de Azevedo (co)redator, Anísio Teixeira e Lourenço Filho.

\section{O Manifesto}

O documento é introduzido colocando a educação como o problema mais grave e mais importante do cenário brasileiro. Não surpreende ao relacionar a educação com a economia, pois o cenário da época era de expansão o que se afirma que "é impossível desenvolver as forças econômicas de produção, sem o preparo intensivo das forças culturais e o desenvolvimento das aptidões à invenção e à iniciativa que são os fatores fundamentais do acréscimo de riquezas de uma sociedade" (MANIFESTO, 1932. p.407). Ainda nos princípios do Manifesto, encontra-se a justificativa do movimento como uma reação contra o empirismo dominante e por isso, o dever de formular em documento público, as bases e diretrizes do movimento (idem, p.409).

A partir do Manifesto, a função da educação passa a assumir caráter biológico. Sua finalidade é de dirigir o desenvolvimento natural e integral do sujeito garantindo escolarização em todos os graus, e submissa aos interesses e necessidades do sujeito. "A escola passa a ser instrumento da sociedade, ou sua representação" (MANIFESTO,1932, p.411).

Sobre os valores mutáveis e imutáveis, traz a relação homem-trabalho. Reconhece que deve formar o homem antes de formar a máquina, porém, afirma que o único método de fazer homens úteis sob todos os aspectos é o trabalho. Essa afirmação deixa explícito o caráter educacional, que por mais renovador que possa ter sido para a época, há de lembrar que continua a fazer parte da linha liberal de educação e, portanto, o fim último da educação, é formar pessoas que possam desempenhar papéis na sociedade.

\section{O Estado face à Educação}

A seção O Estado face a Educação subdividido em mais três seções e discorre acerca da educação ser essencialmente pública, única, laica e coeducação. Tomando como análise o próprio Manifesto é possível compreender que sendo a Educação essencialmente pública, então está sobre a responsabilidade do Estado e não mais somente sob o comando familiar. O Estado agora deve se 
articular em regime cooperativo com outros órgãos ou instituições, mas deve Ele arcar como responsável principal.

Pelo entendimento do público, a gratuidade nos parece ser óbvia, mas o Manifesto não proíbe iniciativas privadas, desde que respeitado o princípio da escola única que significa oficial, ou seja, independentemente de ser privado ou público, os graus de educação devem ter as mesmas bases de Diretrizes e estas devem ser organizadas obedecendo as competências de ordem psicobiológicas dos sujeitos, levando-os ao desenvolvimento máximo, conforme suas aptidões. O obrigatório se restringe até a idade de trabalho, 18 anos. Como é possível de constatar público, gratuito e obrigatório são interdependentes e subordinados entre si. Quanto a laicidade é garantir que no ambiente escolar não aconteçam disputas de ideologias religiosas, tampouco que religiões estejam acima da finalidade educacional visando garantir respeito as diversidades religiosas.

\section{A Função Educacional}

A seção "A função educacional" é dividida em três subseções: unidade, autonomia e descentralização educacional. Traz alguns esclarecimentos quanto a organização, a saber: Unidade: desenvolver ao máximo as capacidades do ser humano até a sua completa formação;

Autonomia: nas dimensões técnica, administrativa e econômica para não sofrer influências externas; Descentralização: atribuir deveres, fiscalização, colaboração.

Dessas seções, pode-se afirmar que estão em pauta até a atualidade. Pois, ainda luta-se por autonomia financeira das escolas e por mais que já existem programas os quais garantem recursos direto nas escolas, sabe-se que ainda é precário diante das necessidades que estas enfrentam. Outra questão que se complementa é a descentralização que por mais que atualmente os sistemas sejam regidos pelo regime de colaboração, ainda há uma forte teoria da burocracia que impede ou dificulta processos administrativos que seriam simples se cada instituição gozasse de liberdade e autonomia para deliberar pareceres.

\section{Do Processo Educativo ao Ponto Nevrágico da Questão}

Vejamos, partindo da análise o próprio Manifesto, como foi desenvolvido ideias conceituais sobre educação, escola, função da educação secundária na Educação Nova.

Pautada ciência, no método experimental e utilizados como instrumentos da escola, esta deve ser favorável a criança seja levado ao trabalho, com todos os recursos possíveis, atenda aos seus 
interesses e necessidades. A escola passará a ser um organismo vivo, uma estrutura social, deve representar uma comunidade em miniatura (MANIFESTO, 1932. p.416). Assim, a educação, de caráter pragmático inerente a própria natureza infantil subordinada aos fatores psicológicos, biológicos, interesses, necessidades e aptidões dos alunos.

Atente-se à contrariedade: é estimulado o trabalho coletivo, mas observa-se as aptidões individuais. Essa contrariedade tem sua raiz ainda nos princípios dos ideais da educação nova: $\mathrm{O}$ Trabalho como elemento Formador, que incentiva a coletividade, mas será pelo desempenho individual o caráter de eficiência (idem, p.417).

Até este ponto é notório que se trata de um plano transformador da educação. Como traz no próprio Manifesto, a Educação está inorganizada, ou seja, não há nem indícios de um sistema educacional, e a partir deste Documento, a História da Educação Brasileira começa a ter um plano específico que mesmo com influências de John Dewey, foi pensado (ao menos a maior parte) para a educação nacional.

Importante destacar ainda o que o Manifesto denominou de Ponto Nevrálgico da Questão, o qual corresponde a estrutura do Plano Educacional e seus níveis: escola infantil ao ensino superior que deveria ser por completo reformada, pois compreendendo o período de pleno desenvolvimento do homem, a educação objetivava desde a formação da personalidade, como desenvolvimento para o trabalho.

Eis que o Manifesto (1932, pág.418) afirma que “a Reforma educacional do ensino secundário contaria com uma Base Comum, o que iria favorecer à democracia educacional". Porém, deve-se ser refletido que, ao passo que o Manifesto é amplamente divulgado como ferramenta que acabaria com a divisão de uma educação baseada nas classes sociais, Ele mesmo defende uma escola secundária de divisão intelectual após 3 anos de educação secundária. Ou seja, a separação ou exclusão por divisão de classes sociais foi criticada visando sua superação. Entretanto, a separação se faz presente devido às condições de aprendizagens e capacidades individuais.

Com isso, o ensino superior, através da Reforma, reconheceu-se a necessidade de transformação na sua forma de organização e de ensino, indo além de profissões liberais, criando ou organizando a Universidade como espaço de investigação científica diversa e formadora de pesquisadores, que atenda as potencialidades dos sujeitos universitários, como também as demandas das profissões existentes, inclusive de formação de professores.

Conforme defendido no Manifesto, esta educação está apoiada num tripé, a saber: criadora de novas ciências, docência e transmissão de conhecimento. Tal tripé traz a função do ensino universitário que consiste não somente na formação profissional de conhecimentos aplicáveis de forma imediata, mas, essencialmente, do desenvolvimento de saberes e aperfeiçoamento do homem. Essência perdida, 
conforme o Manifesto, devido a lacuna - uma base sólida científica - presente na educação secundária de outrora.

Há de ser destacada a situação que fez reconhecer a necessidade de Reforma da educação superior. Atente-se que a raiz da problemática desta educação não está nela própria e sim na educação secundária. Razão pela qual os Pioneiros chamaram de ponto nevrálgico e reconheceram ser na educação superior a redenção desta situação ao conclamarem que seu tripé proporciona a disseminação do "estado de ânimo nacional" levando os sujeitos a, através das ciências, estudarem os grandes problemas nacionais e dispondo de meios para combatê-los. "Fica evidente a função de formar elite intelectual capaz de resolver problemas científicos aos políticos" (Manifesto, 1932. p. 420).

Apesar do caráter democrático amplamente divulgado, o Manifesto é claro e objetivo ao afirmar que uma sociedade será perfeita quanto mais for pesquisada, portanto, deve ser cuidadosamente selecionada a elite intelectual. Agora, não mais pelo caráter econômico, mas pelas capacidades biopsicológicas que favorecerão a educação e o desenvolvimento. À Universidade cabe desenvolver ao máximo as capacidades que são naturais do sujeito devolvendo à sociedade os mais capazes para que estes consigam influenciar socialmente.

Neste contexto, o Manifesto insere a formação de professores no quadro da elite intelectual sob a afirmação que tratam a profissão docente de uma forma diferente, ao discutir a docência como profissão e que por isso, requer formação superior de base, com objetivos e princípios comuns, independentemente do grau de educação que o professor irá atuar.

Percebe-se que os Pioneiros visavam uma base comum de formação como instrumento de conscientizá-los, num sentimento comum para a realização da obra educacional no seu lócus: a escola. Esta que se faz espaço de educação, precisa dar sentido às reformas externas, logo, fez parte da Reforma proposta pelos Pioneiros em ser uma instituição viva, propiciadora e estimuladora do desenvolvimento de aptidões individuais com uso de recursos diversos, espaço de vivências coletivas que preparando para a vida na sociedade precisava reproduzir tais situações em seu interior, valorizando e recrutando a família para fazer parte do processo educativo.

Os ideais fortemente influenciados por John Dewey trazidos ao Brasil através de Anísio Teixeira, objetivaram formar o homem criativo (para o trabalho), desenvolver autonomia para as múltiplas tarefas educacionais, do trabalho e sociais.

Portanto, O Manifesto traz em sua última seção uma forma política de organização: A Democracia. Mesmo diante de uma seção específica foi possível detectar no corpo do Manifesto que o ideal de democracia se fez presente, mesmo que nos discursos. Porém, deve ser compreendido que propor uma educação aberta a todas as classes sociais e selecionar, a rigor as capacidades e aptidões individuais, corre-se o risco de cometer exclusões, pois a proposta não está pautada nas particularidades 
de desenvolvimento, não se discute a razão de uma não aprendizagem e seus fatores intervenientes, apenas valoriza-se a capacidade desenvolvida.

\section{Considerações Finais}

Otimismo pedagógico, A Grande Reforma: assim ficou caracterizado o período da elaboração e divulgação do O Manifesto dos Pioneiros da Educação Nova. Isso aconteceu devido a este Manifesto ser um plano de reforma educacional nacional. Ousado, teve seu surgimento atrelado ao que podemos convencionalmente chamar de estratégia política educacional durante a IV Conferência Nacional de Educação (1931), o qual solicitava imediata transformação da educação nacional em todos os graus de educação sem excetuar aos professores.

Contou com 26 signatários, no entanto, a vanguarda do movimento leva os nomes de Fernando de Azevedo, Anísio Teixeira e Lourenço Filho. A Reforma se fez necessária e urgente por não ter ainda no Brasil uma política educacional sistematizada, de base comum, com articulação entre os graus de educação com objetivos definidos. Em contrapartida, a educação nacional era fortemente dividida por classes e essa forma de divisão foi alvo das propostas de Reforma visando sua superação. Atribuindo à educação secundária como principal mantenedora desta divisão, defendeu como princípio educacional a democracia. No entanto, o que se observou foi uma substituição dos aspectos econômicos pelas aptidões individuais como critério de seleção para acesso e permanência à nova educação.

A educação secundária, denominada de ponto nevrálgico da questão, também recebeu responsabilidade pela necessidade de reformar a educação superior. Pensando-se na articulação que deve ter entre todos os graus, através da Reforma a educação secundária, de acesso a todos deveria ser dividida em dois momentos: o primeiro com base comum e geral e o segundo momento conforme as aptidões individuais, ou seja, ao mais capacitados teriam educação humanística e preparo para a educação superior e os que não estivessem dentro desta capacidade, seguiriam os estudos para formação de habilidades manuais profissionais.

A escola e universidade trazem como função a formação moral, mas deve ao máximo estimular o desenvolvimento das capacidades. Há de ser destacado que a universidade considerada como lócus da elite intelectual, deveria ser criteriosa ao selecionar seus estudantes, pois objetivava o desenvolvimento da sociedade, riquezas, superação dos grandes problemas nacionais e somente seria possível através de pesquisadores universitários capazes de serem esses profissionais. Dentro da elite intelectual, da universidade, os professores das mais diversas áreas que necessariamente precisam passar pela formação superior para exercerem suas atividades de forma consciente e coerente com os objetivos propostos na Reforma. 
Diante da análise do contexto histórico do surgimento do Manifesto dos Pioneiros da Educação Nova, suas propostas reformistas, bem como quem as redigiu é possível verificar que a educação teria sim outros rumos, pois pela primeira vez foi valorizada a formação profissional de professores em regime universitário, ou seja, mais que professores a Reforma objetivou formar pesquisadores capazes de atender satisfatoriamente as demandas impostas pela realidade socioeducacional.

Todavia, substituir formas de seleção/exclusão não pode ter status de nova educação, pois o que se viu foi a modernização do ensino tradicional. Outro ponto que deve ser levantando para reflexão é que esta educação nova é liberal, portanto ela estará sim a serviço da sociedade e de sua organização para o mercado de trabalho. A valorização dos aspectos psicológicos a serem estimulados e desenvolvidos na escola como o aprender, a descoberta, a auto avaliação e a criatividade são características importantes para pensar no desenvolvimento e modernização das forças de trabalho da época que já não se satisfazia com a submissão de comandos das tarefas, mas precisava de espírito com autonomia, criatividade e liberdade para inovar, criar, avançar. Por fim, questionamos: A quem serviram os ideais inovadores e democráticos da educação?

\section{Referências}

AZEVEDO, Fernando de. (Et. Al). O Manifesto dos Pioneiros da Educação Nova. Conferência Nacional de Educação. IV, 1932. Disponível em: <http://download.inep.gov.br/download/70Anos/Manifesto_dos_Pioneiros_Educacao_Nova.pdf $>$. Acesso 03/10/2017.

DÁVILA, Jerry. Diploma de Brancura. Política social racial no Brasil - 1917-1945. São Paulo: UNESP,2006, p. 17-93.

DE OLIVEIRA GOMES, Marco Antônio. Educação e movimento operário na república velha. In: VII Seminário Nacional de Estudos e Pesquisas: História, Sociedade e Educação, 2006, Campinas. Seminário Nacional de Estudos e Pesquisas:? História, Sociedade e Educação no Brasil? - HISTEDBR, 2006. $\quad$ v. $1 . \quad$ p. 173-173. 1 Disponível em: <http://www.histedbr.fe.unicamp.br/acer_histedbr/seminario/seminario7/TRABALHOS/M/Marco\%20 antonio\%20de\%20oliveira\%20gomes.pdf $>$. Acesso em 18 de setembro de 2017.

DEL PRIORE, Mary; VENÂNCIO, Renato Pinto. Uma breve história do Brasil. São Paulo: Planeta, 2010.

MAZZUCO, N. G.; TUlliO, G. A. O Manifesto De 1932- Velha Filosofia No Pensamento Dos Pioneiros Da Educação Nova. In: III Congresso Brasileiro De História Da Educação, 2004, Curitiba. A Educação Escolar - Perspectiva História. Curitiba: Adicvan High Tech Tecnologia Digital Ltda, 2004.

QUEIROZ, F. A. de. Industrialização e Modernização no Brasil: 1930-1964. Geografia (Londrina), Londrina, v. 11, n.1, p. 44-53, 2002. 
SAVIANI, Dermeval. História das ideias pedagógicas no Brasil. 2 eds. rev. e ampl. - Campinas, SP. 2008.

VIEIRA, S. R. Uma Reflexão acerca do Manifesto dos Pioneiros da Educação Nova. In: VII Seminário Nacional de Estudos e Pesquisas: História, Sociedade e Educacão no Brasil, 2006, Campinas. VII Seminário Nacional de Estudos e Pesquisa História, Sociedade e Educação. Campinas: UNICAMP, 2006. v. 1. p. 201-201.

VIDAL, Diana Gonçalves. 80 anos do Manifesto dos Pioneiros da Educação Nova: questões para debate. Disponível em: <http://www.scielo.br/pdf/ep/v39n3/aop1177.pdf >. Acesso 03/10/2017. Educ. Pesqui., São Paulo, v. 39, n. 3, p. 577-588, jul./set. 2013.

\section{Como citar este artigo (Formato ABNT):}

MACÁRIO, Edilânio Rodrigues; BANDEIRA, Ítalo Ramom Santos; MOURA, Kátia Maria de. Leituras Acerca do Manifesto dos Pioneiros da Educação Nova De 1932: Uma Análise para além da Educação. Id on Line Rev.Mult. Psic., 2018, vol.12, n.41, p.677-692. ISSN: 1981-1179.

Recebido: 10/07/2018

Aceito 12/07/2018 